\title{
Benefits of Pulmonary Rehabilitation in Patients With COPD and Normal Exercise Capacity
}

\author{
Chou-Chin Lan MD PhD, Wen-Hua Chu RRT, Mei-Chen Yang MD, \\ Chih-Hsin Lee MD, Yao-Kuang Wu MD, and Chin-Pyng Wu MD PhD
}

\begin{abstract}
BACKGROUND: Pulmonary rehabilitation (PR) is beneficial for patients with COPD, with improvement in exercise capacity and health-related quality of life. Despite these overall benefits, the responses to PR vary significantly among different individuals. It is not clear if PR is beneficial for patients with COPD and normal exercise capacity. We aimed to investigate the effects of PR in patients with normal exercise capacity on health-related quality of life and exercise capacity. METHODS: Twenty-six subjects with COPD and normal exercise capacity were studied. All subjects participated in 12-week, 2 sessions per week, hospital-based, out-patient PR. Baseline and post-PR status were evaluated by spirometry, the St George's Respiratory Questionnaire, cardiopulmonary exercise test, respiratory muscle strength, and dyspnea scores. RESULTS: The mean $\mathrm{FEV}_{1}$ in the subjects was $1.29 \pm 0.47 \mathrm{~L} / \mathrm{min}, 64.8 \pm 23.0 \%$ of predicted. After PR there was significant improvement in maximal oxygen uptake and work rate. Improvements in St George's Respiratory Questionnaire scores of total, symptoms, activity, and impact were accompanied by improvements of exercise capacity, respiratory muscle strength, maximum oxygen pulse, and exertional dyspnea scores (all $P<.05$ ). There were no significant changes in pulmonary function test results $\left(\mathrm{FEV}_{1}, \mathrm{FVC}\right.$, and $\left.\mathrm{FEV}_{1} / \mathrm{FVC}\right)$, minute ventilation, breathing frequency, or tidal volume at rest or exercise after PR. CONCLUSIONS: Exercise training can result in significant improvement in health-related quality of life, exercise capacity, respiratory muscle strength, and exertional dyspnea in subjects with COPD and normal exercise capacity. Exercise training is still indicated for patients with normal exercise capacity. Key words: pulmonary rehabilitation; health-related quality of life; exercise training; COPD; exercise capacity. [Respir Care 2013;58(9):1482-1488. (C) 2013 Daedalus Enterprises]
\end{abstract}

\section{Introduction}

There are many studies about the benefits of pulmonary rehabilitation (PR) in patients with COPD..$^{1-5}$ PR has been shown to lead to improvement in exercise capacity, healthrelated quality of life (HRQL), and work efficiency in patients with COPD. ${ }^{1-3}$ Therefore, PR has been recommended as an integral part of management for these pa-

\footnotetext{
Drs Lan, Yang, Lee, and Yao-Kuang Wu are affiliated with the Division of Pulmonary Medicine; and Wen-Hua Chu is affiliated with the Division of Respiratory Therapy, Taipei Tzu Chi Hospital, Buddhist Tzu Chi Medical Foundation, Taipei, Taiwan. Dr Chin-Pyng Wu is affiliated with the Department of Critical Care Medicine, Li-Shin Hospital, Ping-Jen City, Tao-Yuan County, Taiwan.
}

Drs Yao-Kuang Wu and Chin-Pyng Wu contributed equally to this work. tients. ${ }^{6,7}$ The American Thoracic Society recommends PR for patients with persistent exercise intolerance despite receiving optimal medical therapy. ${ }^{7}$ According to the Global Initiative for Chronic Obstructive Lung Disease (GOLD) consensus document on the management of COPD, PR should be considered in symptomatic patients with a $\mathrm{FEV}_{1}$ below $80 \% .^{8}$

\footnotetext{
The authors have disclosed no conflicts of interest.

Correspondence: Chin-Pyng Wu MD PhD, Department of Critical Care Medicine, Li-Shin Hospital, 77 Kwang-Tai Road, Ping-Jen City, TaoYuan County, Taiwan, Republic of China. E-mail: chinpyng@mail. ndmctsgh.edu.tw.
}

DOI: $10.4187 /$ respcare.02051 
Despite these overall benefits, the responses to PR may vary significantly among individuals. Ngaage et al suggested that PR in end-stage COPD can improve exercise tolerance and physical activity. ${ }^{4}$ Takigawa et al performed PR for subjects with different stages of COPD, and demonstrated that all subjects benefited from PR, regardless of disease severity. ${ }^{9}$ Ergün et al also suggested that PR in the early stages (stages I and II) is as effective as in the late stages (stages III and IV) COPD. ${ }^{5}$ Since PR is beneficial to patients with even mild COPD, it is reasonable to conclude that PR should also be beneficial to symptomatic patients with normal exercise capacity. However, previous studies have been on the different stages of COPD, and not on exercise capacity. There are no studies about PR in subjects with normal exercise capacity. Physicians may mistakenly consider that such subjects have limited improvement because they already have normal exercise capacity. Thus, the benefits of PR in subjects with normal exercise capacity should be investigated.

Since there are no previous studies on the benefits of PR in subjects with normal exercise capacity, the present study attempted to define these issues by investigating the effects of PR in subjects with normal exercise capacity on HRQL, exercise capacity, dyspnea, and respiratory muscle strength. A comprehensive understanding of these outcomes is important to optimize the management of patients with COPD.

\section{Methods}

The research protocol was approved by the ethics committee of the Taipei Tzu Chi Hospital, the Buddhist Tzu Chi Medical Foundation. Signed informed consent was obtained from all subjects.

\section{Subject Selection}

Twenty-six subjects with COPD and normal exercise capacity were recruited from our out-patient clinic, from August 2009 to March 2011. They met the following inclusion criteria: a diagnosis of COPD based on the GOLD staging of the disease ${ }^{10}$; normal exercise capacity, with maximal oxygen uptake $\left(\dot{\mathrm{V}}_{\mathrm{O}_{2}}\right)$ of $85 \%$ by incremental cardiopulmonary exercise test ${ }^{11,12}$; stable from exacerbations, with no worsening of respiratory symptoms (ie, dyspnea, chest tightness, and cough), no increase in the use of rescue medication, and no unscheduled visits due to COPD worsening for at least 3 months ${ }^{13}$; and ability to mobilize independently. The exclusion criteria were: use of oral corticosteroids; history of other lung diseases, including pneumoconiosis, bronchiectasis, pulmonary tuberculosis, primary pulmonary hypertension, pulmonary embolism, interstitial lung disease; and orthopedic, neurologic, or car-

\section{QUICK LOOK}

\section{Current knowledge}

Pulmonary rehabilitation benefits patients with COPD by improving exercise capacity and health-related quality of life (HRQL). However, it is not clear if pulmonary rehabilitation benefits patients with COPD and normal exercise capacity.

\section{What this paper contributes to our knowledge}

Exercise training improved HRQL, exercise capacity, respiratory muscle strength, and exertional dyspnea in patients with COPD and normal exercise capacity, suggesting that exercise training is indicated in these patients.

diovascular impairment that might render the subject incapable of completing the exercise training.

\section{Measurements}

Physiologic parameters were assessed by spirometry, respiratory muscle strength testing (maximal inspiratory pressure $\left[\mathrm{P}_{I \max }\right]$ and maximal expiratory pressure $\left.\left[\mathrm{P}_{\mathrm{Emax}}\right]\right)$, and cardiopulmonary exercise test before and after PR. The HRQL and dyspnea symptom were assessed by the St George's Respiratory Questionnaire (SGRQ) ${ }^{14}$ and dyspnea scores. ${ }^{15}$

\section{Pulmonary Function Test}

Pulmonary function tests for measurement of $\mathrm{FEV}_{1}$ and FVC were made by spirometry (CPFS/D USB, Medical Graphics, St Paul, Minnesota), following the standards of the American Thoracic Society and European Respiratory Society. ${ }^{16,17}$ The best flow-volume loop was used in the final data analysis. Reference equations for $\mathrm{FEV}_{1}$ and $\mathrm{FVC}$ based on the normal populations were made available by Knudson et al. ${ }^{18}$

\section{Respiratory Muscle Strength}

The $\mathrm{P}_{\text {Imax }}$ and $\mathrm{P}_{\text {Emax }}$ were assessed using a standard mouthpiece and a direct dial pressure gauge (MicroRPM, Micro Medical/CareFusion, San Diego, California). $\mathrm{P}_{\text {Imax }}$ was measured at residual volume, and $\mathrm{P}_{\mathrm{Emax}}$ at total lung capacity, according to procedures previously described. ${ }^{19}$ The $\mathrm{P}_{\mathrm{Imax}}$ and $\mathrm{P}_{\mathrm{Emax}}$ were measured several times, and after 4 or 5 attempts, a plateau of values then showed relatively little variability ( $\pm 10 \%$ of reading). ${ }^{20}$ The highest values for $\mathrm{P}_{\mathrm{Imax}}$ and $\mathrm{P}_{\mathrm{Emax}}$ were recorded. ${ }^{19}$ 


\section{Pulmonary Rehabilitation in Patients With COPD and Normal Exercise Capacity}

\section{Cardiopulmonary Exercise Test}

An incremental, symptom-limited exercise test was performed on an electronically braked cycle ergometer (906900, Lode Corival, Groningen, the Netherlands) before and after PR. The standard bicycle exercise ramp work load protocol was according to the method of Wasserman et al. ${ }^{11}$ To stabilize gas measurement, subjects were asked to remain still for at least 3 min before beginning upright graded bicycle exercise testing. The subjects then performed unloaded pedaling for 3 min, followed by the ramp increase in work rate. The work rate increment (10-20 watts/min) was judged for each individual subject by considering age, sex, height, and weight, for obtaining an exercise phase of $8-12 \mathrm{~min} .{ }^{11}$ The subjects were asked to maintain a cycling cadence of 60 revolutions per minute, and were strongly encouraged to achieve their point of maximal exercise.

Expired air was continuously analyzed using a cardiopulmonary diagnostic system (Breeze 6.1, MGC Diagnostics, St Paul, Minnesota) to assess physiologic responses to exercise. $\dot{\mathrm{V}}_{\mathrm{O}_{2}}$, carbon dioxide output, minute ventilation, breathing frequency, tidal volume, $\mathrm{S}_{\mathrm{pO}_{2}}$, end-tidal $\mathrm{P}_{\mathrm{CO}_{2}}$, electrocardiogram, heart rate, and blood pressure were measured continuously during the exercise test. Peak $\dot{\mathrm{V}}_{\mathrm{O}_{2}}$ was expressed as the highest 30 -second average value obtained during the last stage of the exercise test. Dyspnea scores were rated at rest and peak exercise. Anaerobic threshold was assessed using the V-slope method. ${ }^{11}$ Maximal oxygen pulse was calculated by dividing maximal $\dot{\mathrm{V}}_{\mathrm{O}_{2}}$ by maximal heart rate. ${ }^{11}$ The subject's data with maximal exercise was used if the following criteria were met: $85 \%$ of age-predicted heart rate; respiratory exchange ratio

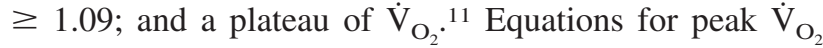
were according to previous references. ${ }^{21,22}$

\section{Health-Related Quality of Life Assessment}

HRQL of these subjects was assessed by the validated Chinese version of the SGRQ. ${ }^{14}$ The SGRQ is a questionnaire designed to measure the influence of chest diseases on HRQL. 14,23,24 The 50 items can be aggregated into an overall score and 3 subscores, for symptoms (8 items), activity (16 items), and impact (26 items). Responses are weighted and scores are calculated by dividing the summed weights by the maximum possible weight, 0 being the best possible score, and 100 the worst. ${ }^{14,23,24}$ The SGRQ has been reported to be valid and reliable in subjects with COPD, asthma, and bronchiectasis. ${ }^{14,23,24}$

\section{Pulmonary Rehabilitation}

All subjects participated in a 12-week, 2 sessions per week, out-patient-based PR program. In each session, for-
Table 1. Baseline Characteristics of Patients With COPD and Normal Exercise Capacity

\begin{tabular}{lc}
\hline \hline Age, $\mathrm{y}$ & $71.0 \pm 10.7$ \\
Body mass index, $\mathrm{kg} / \mathrm{m}^{2}$ & $23.8 \pm 5.1$ \\
COPD stage, no. $(\%)$ & \\
I: mild & $6(23.1)$ \\
II: moderate & $13(50.0)$ \\
III: severe & $7(26.9)$ \\
IV: very severe & $0(0)$ \\
$\mathrm{P}_{\text {Imax }}, \mathrm{cm} \mathrm{H}_{2} \mathrm{O}$ & $68.1 \pm 25.7$ \\
$\mathrm{P}_{\text {Imax }} \%$ of predicted & $73.6 \pm 25.6$ \\
$\mathrm{P}_{\text {Emax }}, \mathrm{cm} \mathrm{H}_{2} \mathrm{O}$ & $109.4 \pm 30.5$ \\
$\mathrm{P}_{\text {Emax }}, \%$ of predicted & $65.2 \pm 20.7$ \\
Major medications, no. $(\%)$ & \\
$\quad$ Theophylline & $20(76.9)$ \\
Inhaled long-acting muscarinic antagonists & $14(53.8)$ \\
Inhaled long-acting $\beta$ agonist plus inhaled corticosteroid & $12(46.2)$ \\
Oral corticosteroid & $0(0)$ \\
\hline \pm Values are mean \pm SD. & \\
$\mathrm{P}_{\text {Imax }}=$ maximum inspiratory pressure & \\
$\mathrm{P}_{\text {Emax }}=$ maximum expiratory pressure & \\
\hline
\end{tabular}

mal education, including breathing retraining, proper use of medications, and self-management skills, was given individually. After the education, the exercise training with lower limb cycle ergometer exercise was given. Exercise sessions were $40 \mathrm{~min}$, and exercise intensity targets were set at high intensity, with $75-100 \%$ of the maximal $\dot{\mathrm{V}}_{\mathrm{O}_{2}}$ observed in the pre-PR incremental exercise test. Sessions were closely monitored by a rehabilitation therapist. We monitored work rate, $\mathrm{S}_{\mathrm{pO}_{2}}$, heart rate, dyspnea scores, and leg fatigue during every exercise training session. During the period of PR, these subjects were not allowed to perform exercise by themselves at home.

\section{Statistical Analysis}

Baseline measurements and results after PR are expressed as mean $\pm \mathrm{SD}$. Paired $t$ tests were used to compare measurements before and after PR in these subjects. A $P$ value $<.05$ was considered to be significant. Statistical analyses was with statistics software (SPSS 18.0, SPSS, Chicago, Illinois).

\section{Results}

\section{Anthropometric and Spirometric Data}

The clinical characteristics and lung function of these subjects with COPD are shown in Table 1. The mean $\mathrm{FEV}_{1} / \mathrm{FVC}$ was $59.4 \pm 14.1 \%$, and the mean $\mathrm{FEV}_{1}$ was $64.8 \pm 23.0 \%$ of predicted. Most subjects had mild to moderate COPD. The $\mathrm{P}_{\text {Imax }}$ and $\mathrm{P}_{\text {Emax }}$ were normal. These 


\section{Pulmonary Rehabilitation in Patients With COPD and Normal Exercise Capacity}

Table 2. Effects of Pulmonary Rehabilitation on Pulmonary Function Tests, Respiratory Muscle Strength, and Health-Related Quality of Life

\begin{tabular}{|c|c|c|c|c|}
\hline & $\begin{array}{c}\text { Before } \\
\text { Pulmonary Rehabilitation }\end{array}$ & $\begin{array}{c}\text { After } \\
\text { Pulmonary Rehabilitation }\end{array}$ & $\begin{array}{c}\text { Mean } \\
\text { Difference }\end{array}$ & $P$ \\
\hline $\mathrm{FEV}_{1} / \mathrm{FVC}, \%$ & $59.4 \pm 14.1$ & $61.5 \pm 15.0$ & 2.1 & .34 \\
\hline $\mathrm{FEV}_{1}, \mathrm{~L}$ & $1.29 \pm 0.47$ & $1.33 \pm 0.46$ & 0.04 & .46 \\
\hline $\mathrm{FEV}_{1}, \%$ predicted & $64.8 \pm 23.0$ & $66.7 \pm 22.3$ & 2.0 & .42 \\
\hline FVC, L & $2.24 \pm 0.79$ & $2.21 \pm 0.66$ & -0.03 & .75 \\
\hline FVC, $\%$ predicted & $88.3 \pm 34.5$ & $87.7 \pm 32.0$ & -0.6 & .87 \\
\hline $\mathrm{P}_{\text {Imax }}, \mathrm{cm} \mathrm{H}_{2} \mathrm{O}$ & $68.1 \pm 25.7$ & $75.9 \pm 24.0$ & 7.8 & .02 \\
\hline $\mathrm{P}_{\text {Imax }}, \%$ of predicted & $73.6 \pm 25.6$ & $82.5 \pm 22.2$ & 8.9 & .02 \\
\hline $\mathrm{P}_{\text {Emax }}, \mathrm{cm} \mathrm{H}_{2} \mathrm{O}$ & $109.4 \pm 30.5$ & $121.4 \pm 37.3$ & 12.0 & .03 \\
\hline $\mathrm{P}_{\text {Emax }}, \%$ of predicted & $65.2 \pm 20.7$ & $71.5 \pm 20.4$ & 6.3 & .04 \\
\hline \multicolumn{5}{|l|}{ SGRQ scores } \\
\hline Total & $39.8 \pm 16.3$ & $28.6 \pm 16.0$ & -12.4 & $<.001$ \\
\hline Symptoms & $47.8 \pm 23.9$ & $35.5 \pm 25.9$ & -7.8 & .03 \\
\hline Activity & $50.6 \pm 18.7$ & $42.8 \pm 18.2$ & -12.5 & $<.001$ \\
\hline Impact & $31.2 \pm 20.1$ & $18.7 \pm 15.3$ & -11.1 & $<.001$ \\
\hline $\begin{array}{l}\text { Values are mean } \pm \text { SD. } \\
\mathrm{P}_{\text {Imax }}=\text { maximum inspiratory } \\
\mathrm{P}_{\text {Emax }}=\text { maximum expiratory } \\
\text { SGRQ }=\text { St George's Respirat }\end{array}$ & & & & \\
\hline
\end{tabular}

subjects had no previous participation in home-based or hospital-based PR.

\section{Changes in HRQL With Pulmonary Rehabilitation}

Table 2 shows the SGRQ scores: total, symptoms, activity, and impact before and after PR. There were significant improvements in all domains of SGRQ (all $P<.001$ ). The mean changes of scores of all domains were more that 4 units, which was associated with clinical importance. ${ }^{25}$

\section{Changes in Lung Function and Respiratory Muscle Strength With Pulmonary Rehabilitation}

There were no significant changes in pulmonary function test results $\left(\mathrm{FEV}_{1}, \mathrm{FVC}\right.$, and $\left.\mathrm{FEV}_{1} / \mathrm{FVC}\right)$ after 12 weeks of PR, as shown in Table 2. However, respiratory muscle strength $\left(\mathrm{P}_{\text {Imax }}\right.$ and $\left.\mathrm{P}_{\text {Emax }}\right)$ was significantly improved $(P<.05)$.

\section{Changes of Exercise Capacity, Cardiorespiratory Function and Dyspnea With Pulmonary Rehabilitation}

The post-PR changes of exercise capacity, cardiorespiratory function, and dyspnea are shown in Table 3. All the subjects had normal maximal $\dot{\mathrm{V}}_{\mathrm{O}_{2}}$ and work rate before PR. After PR there were still significant improvements in maximal $\dot{\mathrm{V}}_{\mathrm{O}_{2}}$ (mean increase of $101.3 \mathrm{~mL} / \mathrm{min}, P=.001$ ) and work rate (mean increase of 8.2 watts, $P=.001$ ). Ventilation, heart rate, and mean blood pressure were un- changed following PR. The maximum oxygen pulse at maximum exercise was significantly increased with PR $(P=.02)$. The $\mathrm{S}_{\mathrm{pO}_{2}}$ and end-tidal $\mathrm{P}_{\mathrm{CO}_{2}}$ at peak exercise did not significantly change after PR. Although dyspnea scores at rest were low and did not change significantly with PR, dyspnea at end-exercise was significantly improved after PR $(P=.01)$.

\section{Discussion}

In this study our primary aim was to evaluate the effects of PR in subjects with COPD and normal exercise capacity. Clinicians may hesitate to recommend PR to these subjects, considering their already normal exercise capacity. However, we have shown that subjects with normal exercise capacity who participated in PR still had substantial improvements in HRQL, with decreased SGRQ total, symptom, activity, and impact scores. The exercise capacity and level of exertional dyspnea also showed significant improvement. Their respiratory muscle strength was normal at baseline and also improved after PR. The goals of PR in patients with COPD are to reduce symptoms, improve activity, and restore the highest level of independent function.6,26 As such, PR still offers important benefits for patients with normal exercise capacity, and, conversely, patients with normal exercise capacity are still suitable for PR.

Impaired functional status and dyspnea are pivotal features of COPD. ${ }^{27}$ In this study, subjects with normal exercise capacity (peak $\dot{\mathrm{V}}_{\mathrm{O}_{2}} 91.6 \%$ ) still had an $8.4 \%$ improvement in peak $\dot{\mathrm{V}}_{\mathrm{O}_{2}}$ after PR. The degree of improve- 


\section{Pulmonary Rehabilitation in Patients With COPD and Normal Exercise Capacity}

Table 3. Effect of Pulmonary Rehabilitation on Exercise Capacity, Cardiorespiratory Function, and Dyspnea

\begin{tabular}{|c|c|c|c|c|}
\hline & $\begin{array}{c}\text { Before } \\
\text { Pulmonary Rehabilitation }\end{array}$ & $\begin{array}{c}\text { After } \\
\text { Pulmonary Rehabilitation }\end{array}$ & $\begin{array}{c}\text { Mean } \\
\text { Difference }\end{array}$ & $P$ \\
\hline Work rate, watts & $82.1 \pm 30.4$ & $90.3 \pm 32.7$ & 8.2 & .001 \\
\hline Work rate, $\%$ predicted & $97.8 \pm 15.9$ & $108.6 \pm 18.8$ & 10.8 & .003 \\
\hline$\dot{\mathrm{V}}_{\mathrm{O}_{2}}, \mathrm{~mL} / \mathrm{min}$ & $1,232.6 \pm 327.9$ & $1,334.0 \pm 359.3$ & 101.3 & .001 \\
\hline$\dot{\mathrm{V}}_{\mathrm{O}_{2}}, \%$ predicted & $91.6 \pm 8.2$ & $100.0 \pm 12.6$ & 7.9 & .001 \\
\hline$\dot{\mathrm{V}}_{\mathrm{E}}, \mathrm{L} / \mathrm{min}$ & $40.2 \pm 13.2$ & $39.3 \pm 12.4$ & -0.9 & .52 \\
\hline $\mathrm{V}_{\mathrm{T}}, \mathrm{mL}$ & $1,152.8 \pm 394.6$ & $1,153.4 \pm 406.7$ & 0.6 & .99 \\
\hline$\dot{\mathrm{V}}_{\mathrm{E}} / \mathrm{V}_{\mathrm{CO}_{2}}$ & $33.6 \pm 7.5$ & $32.3 \pm 7.8$ & -1.4 & .16 \\
\hline Heart rate, beats/min & $134.5 \pm 14.9$ & $137.4 \pm 19.9$ & 3.0 & .36 \\
\hline Mean blood pressure, $\mathrm{mm} \mathrm{Hg}$ & $109.6 \pm 15.7$ & $110.3 \pm 15.1$ & 0.7 & .72 \\
\hline Oxygen pulse, mL/beat & $9.2 \pm 2.5$ & $9.8 \pm 2.7$ & 0.6 & .02 \\
\hline $\mathrm{S}_{\mathrm{pO}_{2}}, \%$ & $93.9 \pm 3.1$ & $94.0 \pm 2.9$ & 0.1 & .79 \\
\hline $\mathrm{P}_{\mathrm{ETCO}_{2}}, \mathrm{~mm} \mathrm{Hg}$ & $39.8 \pm 8.3$ & $41.2 \pm 6.8$ & 1.4 & .28 \\
\hline Exertional dyspnea score & $5.7 \pm 1.3$ & $4.8 \pm 2.0$ & -0.9 & .01 \\
\hline $\begin{array}{l}\text { Values are mean } \pm \mathrm{S} D \\
\dot{\mathrm{V}}_{\mathrm{O}_{2}}=\text { oxygen uptake } \\
\mathrm{V}_{\mathrm{T}}=\text { tidal volume } \\
\mathrm{V}_{\mathrm{E}}=\text { minute ventilation } \\
\dot{\mathrm{V}}_{\mathrm{CO}_{2}}=\text { carbon dioxide clearance } \\
\mathrm{P}_{\mathrm{ETCO}_{2}}=\text { end-tidal } \mathrm{P}_{\mathrm{CO}_{2}}\end{array}$ & & & & \\
\hline
\end{tabular}

ment in exercise capacity is similar to previous studies of PR in different populations of COPD. Performing PR in underweight $\left(\mathrm{FEV}_{1} 52.8 \%\right.$, peak $\left.\dot{\mathrm{V}}_{\mathrm{O}_{2}} 72.7 \%\right)$ and normal weight $\left(\mathrm{FEV}_{1} 51.5 \% \text {, peak } \dot{\mathrm{V}}_{\mathrm{O}_{2}} 69.4 \%\right)^{3}$ subjects, the improvements in peak $\dot{\mathrm{V}}_{\mathrm{O}_{2}}$ were $9.0 \%$ and $5.8 \%$, respectively. ${ }^{3}$ Pitta et al performed 3 months of PR in subjects with $\mathrm{COPD}\left(\mathrm{FEV}_{1} 46 \%\right.$, peak $\left.\dot{\mathrm{V}}_{\mathrm{O}_{2}} 63 \%\right)$ and showed a $7 \%$ increase in peak $\dot{\mathrm{V}}_{\mathrm{O}_{2}}$, with improved muscle force, HRQL, and functional status. ${ }^{28}$ Bianchi et al performed 4 weeks of PR in subjects with COPD $\left(\mathrm{FEV}_{1} 52.7 \%\right.$, peak $\left.\dot{\mathrm{V}}_{\mathrm{O}_{2}} 68.8 \%\right)$, and found that PR resulted in $4.5 \%$ improvement in peak $\dot{\mathrm{V}}_{\mathrm{O}_{2}}$. They posited that PR enabled subjects to tolerate a greater amount of restrictive dynamic ventilatory defect. ${ }^{29}$ In the present study, subjects with COPD and normal exercise capacity benefitted from PR, with improving exercise capacity. Exercise capacity is important because peak $\dot{\mathrm{V}}_{\mathrm{O}_{2}}$ significantly correlates with mortality in subjects with COPD. ${ }^{30}$ Previous studies also suggest that PR improves hospitalization and mortality in subjects with COPD. ${ }^{31,32}$ However, the benefit of PR on disease progression and mortality in subjects with already normal exercise capacity remains unclear. Further studies about the benefit of PR on survival in subjects with normal exercise capacity are warranted.

Aside from improving exercise capacity, PR also improved the level of exertional dyspnea. The dyspnea scores at end-exercise were 5.7 points before $\mathrm{PR}$ and 4.8 points after PR. After PR the level of exertional dyspnea in these subjects was near that of healthy subjects. ${ }^{33,34}$

The subjects with COPD in the current study had a normal exercise capacity before PR and they were able to perform high intensity exercise training. An important factor influencing the benefits of PR is training intensity. ${ }^{2,6,7}$ In a previous study, only high intensity exercise training resulted in a significant increase in maximal $\mathrm{V}_{\mathrm{O}_{2}}{ }^{2}$ Casaburi et al also showed that only high intensity exercise training can improve cardiovascular and peripheral muscle function. ${ }^{35}$ Therefore, high intensity exercise training can result in a greater physiological benefit. We suspect that the high intensity exercise training contributed to the benefits observed in the subjects with normal exercise capacity.

The mechanisms of benefits of PR should be addressed. In previous studies the combination of improved mechanical efficiency, improved respiratory and skeletal muscle strength, ${ }^{36}$ adaptations in breathing pattern, ${ }^{37}$ desensitization to dyspnea, ${ }^{37}$ and consequently reduced dynamic hyperinflation, ${ }^{38}$ all contributed to the benefits of PR. It is not clear if the mechanisms of benefit for subjects with normal exercise capacity are the same as in previous studies. In the current study, improvement of respiratory muscle strength after PR was found, and this is one possible mechanism for benefits of PR in these patients. Further studies about PR on dynamic hyperinflation, peripheral muscle strength, adaptations in breathing pattern, and desensitization to dyspnea should be conducted in subjects with normal exercise capacity.

In this study respiratory muscle strength was normal, and we did not perform specific respiratory muscle training. However, general exercise training improved subjects' respiratory muscle strength. Previous study suggests that respiratory muscle training in subjects with $\mathrm{P}_{\text {Imax }}$ below 


\section{Pulmonary Rehabilitation in Patients With COPD and Normal Exercise Capacity}

$60 \mathrm{~cm} \mathrm{H}_{2} \mathrm{O}$ can allow optimal benefits. ${ }^{39}$ However, according to the current study, subjects with normal respiratory muscle strength still benefit from PR. One previous study on normal subjects without respiratory muscle weakness also revealed the same result. ${ }^{40}$ Improvement of respiratory muscle strength is important in that it associates with the reduction in dyspnea. ${ }^{41-43}$ Mechanisms about improvement of respiratory muscle strength after general exercise training are not quite clear. Since exercise increases ventilation by more than 12 -fold, it is expected that exercise training will constitute a training load to the respiratory muscle. ${ }^{41}$

\section{Limitations of the Study}

The present study has some limitations. First, the study defined normal exercise capacity based on maximal $\dot{\mathrm{V}}_{\mathrm{O}_{2}}$ by cardiopulmonary exercise test. The comprehensive assessments of exercise capacity include peripheral muscle function, functional exercise capacity (6-min walk test), and the level of physical activity in daily life. ${ }^{43}$ However, none of these parameters was measured in this study. Second, lung volume changes were also not measured before and after PR. Thus, lung volume changes like dynamic hyper-inflation remain unknown.

\section{Conclusions}

We analyzed the benefits of PR for subjects with COPD and normal exercise capacity. PR did result in significant improvements in HRQL, exercise capacity, exertional dyspnea, and respiratory muscle strength. Our study suggests that PR may still be indicated for patients with COPD and normal exercise capacity. PR should be part of the clinical management of patients with COPD, even for those with normal exercise capacity. However, benefits on disease progression, hospitalization, and survival for these patients remain unknown.

\section{REFERENCES}

1. Franssen FM, Broekhuizen R, Janssen PP, Wouters EF, Schols AM. Effects of whole-body exercise training on body composition and functional capacity in normal-weight patients with COPD. Chest 2004;125(6):2021-2028.

2. Hsieh MJ, Lan CC, Chen NH, Huang CC, Wu YK, Cho HY, et al. Effects of high-intensity exercise training in a pulmonary rehabilitation programme for patients with chronic obstructive pulmonary disease. Respirology 2007;12(3):381-388.

3. Lan CC, Yang MC, Lee CH, Huang YC, Huang CY, Huang KL, et al. Pulmonary rehabilitation improves exercise capacity and quality of life in underweight patients with chronic obstructive pulmonary disease. Respirology 2011;16(2):276-283.

4. Ngaage DL, Hasney K, Cowen ME. The functional impact of an individualized, graded, outpatient pulmonary rehabilitation in endstage chronic obstructive pulmonary disease. Heart Lung 2004;33(6): 381-389.
5. Ergün P, Kaymaz D, Günay E, Erdoğan Y, Turay UY, Demir N, et al. Comprehensive out-patient pulmonary rehabilitation: treatment outcomes in early and late stages of chronic obstructive pulmonary disease. Ann Thorac Med 2011;6(2):70-76.

6. Ries AL, Bauldoff GS, Carlin BW, Casaburi R, Emery CF, Mahler DA, et al. Pulmonary rehabilitation: joint ACCP/AACVPR evidencebased clinical practice guidelines. Chest 2007;131(5 Suppl):4S-42S.

7. ATS/ERS Pulmonary Rehabilitation Writing Committee. American Thoracic Society/European Respiratory Society statement on pulmonary rehabilitation. Am J Respir Crit Care Med 2006;173(12): 1390-1413.

8. Rabe KF, Hurd S, Anzueto A, Barnes PJ, Buist SA, Calverley P, et al. Global strategy for the diagnosis, management, and prevention of chronic obstructive pulmonary disease. Am J Respir Crit Care Med 2007;176(6):532-555

9. Takigawa N, Tada A, Soda R, Takahashi S, Kawata N, Shibayama $\mathrm{T}$, et al. Comprehensive pulmonary rehabilitation according to severity of COPD. Respir Med 2007;101(2):326-332.

10. Global Initiative for Chronic Obstructive Lung Disease (GOLD). Global strategy for the diagnosis, management and prevention of chronic pulmonary disease, 2011. http://www.goldcopd.org/Guidelines/ guidelines-resources.html. Accessed June 21, 2013.

11. Wasserman K, Hansen JE, Sue DY, Stringer WW, Whipp BJ. Principles of exercise testing and interpretation: including pathophysiology and clinical applications. Philadelphia: Lippincott Williams \& Wilkins; 2005.

12. ATS/ACCP Statement on cardiopulmonary exercise testing. American Thoracic Society; American College of Chest Physicians. Am J Respir Crit Care Med 2003;167(2):211-277.

13. Burge S, Wedzicha JA. COPD exacerbations: definitions and classifications. Eur Respir J 2003;41(Suppl):46S-53S.

14. Wang KY, Chiang CH, Maa SH, Shau WY, Tarn YH. Psychometric assessment of the Chinese language version of the St. George's Respiratory Questionnaire in Taiwanese patients with bronchial asthma. J Formos Med Assoc 2001;100(7):455-460.

15. Kendrick KR, Baxi SC, Smith RM. Usefulness of the modified 0-10 Borg scale in assessing the degree of dyspnea in patients with COPD and asthma. J Emerg Nurs 2000;26(3):216-222.

16. American Thoracic Society. Standardization of spirometry. Am J Respir Crit Care Med 1995;152(3):1107-1136.

17. Miller MR, Crapo R, Hankinson J, Brusasco V, Burgos F, Casaburi $\mathrm{R}$, et al. General considerations for lung function testing. Eur Respir J 2005;26(1):153-161.

18. Knudson RJ, Slatin RC, Lebowitz MD, Burrows B. The maximal expiratory flow-volume curve. Normal standards, variability, and effects of age. Am Rev Respir Dis 1976;113(5):587-600.

19. American Thoracic Society; European Respiratory Society. ATS/ ERS statement on respiratory muscle testing. Am J Respir Crit Care Med 2002;166(4):518-624

20. McConnell AK, Copestake AJ. Maximum static respiratory pressures in healthy elderly men and women: issues of reproducibility and interpretation. Respiration 1999;66(3):251-258.

21. Jones NL, Makrides L, Hitchcock C, Chypchar T, McCartney N. Normal standards for an incremental progressive cycle ergometer test. Am Rev Respir Dis 1985;131(5):700-708.

22. Hansen JE, Sue DY, Wasserman K. Predicted values for clinical exercise testing. Am Rev Respir Dis 1984;129(2 Pt 2):S49-S55.

23. Wilson CB, Jones PW, O'Leary C, Cole PJ, Wilson R. Validation of the St. George's Respiratory Questionnaire in bronchiectasis. Am J Respir Crit Care Med 1997;156(2 Pt 1):536-541.

24. Jones PW, Brusselle G, Dal Negro RW, Ferrer M, Kardos P, Levy ML, et al. Health-related quality of life in patients by COPD severity within primary care in Europe. Respir Med 2011;105(1):57-66. 


\section{Pulmonary Rehabilitation in Patients With COPD and Normal Exercise Capacity}

25. Jones PW. Interpreting thresholds for a clinically significant change in health status in asthma and COPD. Eur Respir J 2002; 19(3):398-404.

26. Garvey C, Fromer L, Saver DF, Yawn BP. Pulmonary rehabilitation: an underutilized resource in primary COPD care. Phys Sports Med 2010;38(4):54-60

27. Janssens T, De Peuter S, Stans L, Verleden G, Troosters T, Decramer $\mathrm{M}$, et al. Dyspnea perception in COPD: association between anxiety, dyspnea-related fear, and dyspnea in a pulmonary rehabilitation program. Chest 2011;140(3):618-625.

28. Pitta F, Troosters T, Probst VS, Langer D, Decramer M, Gosselink $\mathrm{R}$. Are patients with COPD more active after pulmonary rehabilitation? Chest 2008;134(2):273-280.

29. Bianchi R, Gigliotti F, Romagnoli I, Lanini B, Castellani C, Binazzi $\mathrm{B}$, et al. Impact of a rehabilitation program on dyspnea intensity and quality in patients with chronic obstructive pulmonary disease. Respiration 2011;81(3):186-195.

30. Oga T, Nishimura K, Tsukino M, Sato S, Hajiro T. Analysis of the factors related to mortality in chronic obstructive pulmonary disease: role of exercise capacity and health status. Am J Respir Crit Care Med 2003;167(4):544-549.

31. Puhan MA, Scharplatz M, Troosters T, Steurer J. Respiratory rehabilitation after acute exacerbation of COPD may reduce risk for readmission and mortality: a systematic review. Respir Res 2005;6: 54.

32. Bowen JB, Votto JJ, Thrall RS, Haggerty MC, Stockdale-Woolley R, Bandyopadhyay T, et al. Functional status and survival following pulmonary rehabilitation. Chest 2000;118(3):697-703.

33. O'Donnell DE, Bertley JC, Chau LK, Webb KA. Qualitative aspects of exertional breathlessness in chronic airflow limitation: pathophysiologic mechanisms. Am J Respir Crit Care Med 1997;155(1): 109-115.
34. O'Donnell DE. Hyperinflation, dyspnea, and exercise intolerance in chronic obstructive pulmonary disease. Proc Am Thorac Soc 2006; 3(2):180-184

35. Casaburi R, Patessio A, Ioli F, Zanaboni S, Donner CF, Wasserman $\mathrm{K}$. Reductions in exercise lactic acidosis and ventilation as a result of exercise training in patients with obstructive lung disease. Am Rev Respir Dis 1991;143(1):9-18.

36. Sala E, Roca J, Marrades RM, Alonso J, Gonzalez De Suso JM, Moreno A, et al. Effects of endurance training on skeletal muscle bioenergetics in chronic obstructive pulmonary disease. Am J Respir Crit Care Med 1999;159(6):1726-1734.

37. Gigliotti F, Coli C, Bianchi R, Romagnoli I, Lanini B, Binazzi B, et al. Exercise training improves exertional dyspnea in patients with COPD: evidence of the role of mechanical factors. Chest 2003; 123(6): 1794-1802.

38. Casaburi R, Porszasz J, Burns MR, Carithers ER, Chang RS, Cooper CB. Physiologic benefits of exercise training in rehabilitation of patients with severe chronic obstructive pulmonary disease. Am J Respir Crit Care Med 1997;155(5):1541-1551.

39. Crisafulli E, Costi S, Fabbri LM, Clini EM. Respiratory muscles training in COPD patients. Int J Chron Obstruct Pulmon Dis 2007; 2(1): $19-25$.

40. Robinson EP, Kjeldgaard JM. Improvement in ventilatory muscle function with running. J Appl Physiol 1982;52(6):1400-1406.

41. Decramer M. Response of the respiratory muscles to rehabilitation in COPD. J Appl Physiol 2009;107(3):971-976.

42. Hill K, Jenkins SC, Hillman DR, Eastwood PR. Dyspnoea in COPD: can inspiratory muscle training help? Aust J Physiother 2004;50(3): 169-180.

43. Probst VS, Kovelis D, Hernandes NA, Camillo CA, Cavalheri V, Pitta F. Effects of 2 exercise training programs on physical activity in daily life in patients with COPD. Respir Care 2011;56(11):17991807. 